\title{
Dr. Dehlin, et al reply
}

To the Editor:

It was with great interest that we read the letter from Watson and colleagues ${ }^{1}$ describing their investigation of how a primary care diagnosis of gout compares to a primary care diagnostic rule for gout and the 1977 American Rheumatism Association (ARA) classification criteria of acute arthritis of primary gout. They present positive predictive values (PPV) of $74 \%$ for the diagnostic rule and $80 \%$ for the ARA criteria. We were not surprised by the vast lack of urate values. Almost $47 \%$ did not have a serum urate level recorded in their medical record. It is troublesome that this mandatory factor for development of gout is not controlled in almost half of the cases. Further, we noticed that presence of tophi was quite low in the population (only $2.4 \%$ ), but this may reflect the medical records in primary care rather than the actual prevalence, which would be considerably higher. The lack of urate levels and the low prevalence of tophus in the medical records lead to an underestimation of the PPV, as the authors also mention. Thus, we must concur that the vast majority of gout cases in primary care fulfill classification criteria and are valid for research purposes ${ }^{2}$.

MATS DEHLIN, MD, Associate Professor, Department of Rheumatology and Inflammation Research, Sahlgrenska Academy, University of Gothenburg; ANTON J. LANDGREN ${ }^{\circ}$, MD, PhD student, Department of Rheumatology and Inflammation Research, Sahlgrenska Academy, University of Gothenburg; ULRIKA BERGSTEN, PhD, Nurse, R\&D Department at Region Halland, Halmstad; LENNART T.H. JACOBSSON, MD, Professor, Department of Rheumatology and Inflammation Research, Sahlgrenska Academy, University of Gothenburg, Gothenburg, Sweden. Address correspondence to Dr. M. Dehlin, Guldhedsgatan 10A, 40530 Gothenburg, Sweden.E-mail: mats.dehlin@vgregion.se

\section{REFERENCES}

1. Watson L, Muller S, Roddy E. Primary care diagnosis of gout compared to a primary care diagnostic rule for gout and to classification criteria. J Rheumatol 2019;46:1542.

2. Dehlin M, Landgren AJ, Bergsten U, Jacobsson LTH. The validity of gout diagnosis in primary care - results from a patient survey. J Rheumatol 2019 Mar 22 [in press].

First Release July 15 2019; J Rheumatol 2019;46:11;

doi:10.3899/jrheum.190552 